\section{NU UNA Kastamonu Eğitim Dergisi Kastamonu Education Journal}

Eylül 2019 Cilt:27 Sayı:6

kefdergi.kastamonu.edu.tr
Başvuru Tarihi/Received: 23.05.2018

Kabul Tarihi/Accepted: 06.02.2019

DOI: $10.24106 /$ kefdergi.3100

\title{
Türkiye'de Özel Eğitim Alanında Değerlendirme Süreci
}

\section{Special Education Evaluation Process in Turkey}

\section{Öz}

\author{
Samed YENIOĞLU ${ }^{1}$, Kübra SAYAR ${ }^{2}$, Hasan KÖSE ${ }^{3}$, Nevin GÜNER-YILDIZ ${ }^{4}$
}

Bu çalışma, ülkemizde özel eğitim alanında doğum öncesi ve doğum sonrası dönemlerde hangi araçlarla ve nasıl değerlendirme yapıldığını ortaya koymayı amaçlayan bir derleme makalesidir. Çalışmada, Türkiye'de doğum öncesi dönemden başlayarak okul dönemini de içine alan süreçte yürütülen tanılama ve değerlendirme uygulamaları ile bu uygulamalarda kullanılan değerlendirme araçlarının özellikleri tanıtılmaya çalışılmıştı. Bireyin gelişiminin izlenmesi, risk altında olanların belirlenmesi, gerekli önlemlerin alınması ve gereksinim duyulan türde programların hazırlanabilmesi için farklı dönemlerde farklı değerlendirme yöntemlerinden yararlanılmaktadır. Çocuğun gelişimi için yapılabilecekler konusunda aileye ve uzmanlara dayanak sağlayan bu değerlendirmeler, doğum öncesi dönemden başlamakta, bebeklik, erken çocukluk ve okul döneminde devam etmektedir. Uygun yapılan değerlendirme ile gereksinime yönelik hazırlanan plan sayesinde hem zaman tasarrufu sağlanmakta hem de mümkün olan en erken dönemde etkili müdahaleye başlanmaktadır.

Anahtar Kelimeler: özel eğitim, değerlendirme, özel gereksinimli çocuk, risk altındaki çocuk.

\section{Abstract}

In this review we aim to determine how and with which tools the evaluation methods applied in Turkey are used in the prenatal and postnatal periods. In this study, the diagnostic and evaluation implementations used in the process which includes the prenatal period and the school period in Turkey and the characteristics of the evaluation instruments used in these implementations have been tried to be introduced. In order to monitor the development of the children, to identify those at risk, to take the necessary precautions and to prepare the required programs, different evaluation methods are used at different periods. These evaluations, which provide support for families and specialists what they can do for the development of the child, begins with the prenatal period, and continue during infancy, early childhood and school periods. With an appropriate evaluation and a needs-oriented plan saving of time is provided and effective intervention is started as early as possible.

Keywords: special education, evaluation, child with special needs, child at risk.

1. Osmangazi Üniversitesi, Eğitim Fakültesi, Özel Eğitim Bölümü, Eskişehir, Türkiye; https://orcid.org/0000-0002-2227-9132

2. Osmangazi Üniversitesi, Eğitim Fakültesi, Özel Eğitim Bölümü, Eskişehir, Türkiye; https://orcid.org/0000-0003-0901-3660

3. Osmangazi Üniversitesi, Eğitim Fakültesi, Özel Eğitim Bölümü, Eskişehir, Türkiye; https://orcid.org/0000-0002-0923-3711

4. Osmangazi Üniversitesi, Eğitim Fakültesi, Özel Eğitim Bölümü, Eskişehir, Türkiye; https://orcid.org/0000-0002-9135-6429

Atıf / Citation: Yenioğlu, S., Sayar, K., Köse, H., \& Güner-Yıldız, N. (2019). Türkiye'de özel eğitim alanında değerlendirme süreci. Kastamonu Education Journal, 27(6), 2379-2389. doi:10.24106/kefdergi.3100 


\section{Extended Abstract}

In this review we aim to determine how and with which tools the evaluation methods applied in Turkey are used in the prenatal and postnatal periods. In addition, it is thought that this study will guide the families who have children with special needs, teachers and experts working in this field.

The fundamental bases of the legal provisions related to special education in Turkey are "Decree Law Numbered 573 on Special Education" and "Special Education Services Regulation". According to the Special Education Services Regulation updated by the Ministry of National Education in 2018, the individual who needs special education is defined as the "individual who significantly differs from the expected level of his/her peers in terms of his/her individual and developmental characteristics and educational competencies". According to Decree Law No. 573 requires the early start of the education of individuals in need of special education. In order to start early education, the individual needs to be evaluated and necessary services needs to be identified. For this purpose, various types of evaluations are carried out to monitor the development of the individual, to identify those in the risk group, to take the necessary precautions and to prepare the necessary intervention programs (Sucuoğlu, 2012). The evaluation of the individual begins in the prenatal period. The newborn screening programs of the Ministry of Health are implemented in the newborn and postnatal period. For children whose developmental disability cannot be determined during this period, various screening and evaluation studies are conducted during early childhood and school period. (Tekin-iftar, 2011; Yüreğir, Büyükkurt, Koç, \& Pazarbaşı, 2012; Özaltun, Güler, \& Şengelen, 2015).

Screening, the first step in the evaluation process, is the process used for early identification and monitoring of individuals with disability or are at risk (Gürsel, 2010). The next step is the medical diagnosis. In medical diagnosis, it is first determined whether the child has a disability. If any kind of disability is determined, the place, grade and reasons of the injuries causing this disability are defined. And finally, in educational diagnosis, the characteristics of the individual in all developmental and disciplinary fields are examined (Baykoç Dönmez, 2011). Educational assessment in Turkey is done by Guidance and Research Centers (Rehberlik Araştirma Merkezleri- RAM) linked to the Ministry of National Education (Diken, 2011).

\section{Screening and Diagnosis in the Prenatal Period}

Prenatal screening is the examination of some genetic diseases by molecular and biochemical methods of fetal samples taken by various methods during early pregnancy (Lo \& Chiu, 2007). With these examinations, it is possible to determine the fetus which is at risk for hereditary disorders and neural tube defects which may cause mental retardation at early stage of pregnancy. The tests performed in the prenatal period are divided into two categories as screening and diagnosis tests (Tekin-iftar, 2011). Screening tests include ultrasonographic fetal imaging and biochemical tests with blood samples taken from the mother. Although screening tests only help to identify infants in the risk group (Ergün, 2007), diagnosis tests provide to make a definitive diagnosis (Sürmeliler, 2005; Tekin-iftar, 2011).

\section{Newborn and Postnatal Screening and Diagnosis}

Postnatal period is an important and risky period in human life (Ergün, 2007). Therefore, the Ministry of Health is applying Early Newborn Screening Program, Newborn Hearing Screening Program and Developmental Dysplasia Early Diagnosis and Treatment Program to all infants for early screening and diagnosis (Bolat \& Genç, 2012; Özaltun, Güler, \& Şengelen, 2015).

In the newborn screening program, blood samples taken from the heels of newborns, are examined to determine whether they have some diseases such as congenital hypothyroidism, phenylketonuria, biodynase deficiency and cystic fibrosis which may adversely affect their health and development. The diseases recognized in these studies can lead to mental retardation, hearing loss, organ damage, and even death in some cases, if not intervened early.

Newborn Hearing Screening Program is implemented to every new born baby in Turkey. If the hearing loss is not diagnosed early and the rehabilitation program is not initiated, individuals with hearing impairment may experience not only problems in their language and speech developments but also problems in their social and psychological developments. Hearing test for diagnosis is implemented to the baby 24 hours after birth. Appropriate hearing aids should be worn in case of hearing loss (Bolat \& Genç, 2012).

Developmental Hip Dysplasia (hip replacement) scan is applied to all newborn infants. It can be completely prevented with early diagnosis and treatment (GKD Tarama Programı, 2013). For early diagnosis one month old infants are examined by family physicians and referred to orthopedic clinic if it is necessary (Özaltun, Güler ve Şengelen, 2015).

\section{Screening, Diagnosis and Evaluation in Early Childhood and School Age Children}

The importance of early intervention in special education is emphasized by many researchers (Birkan, 2002a; Kağıtçıbaşı, Sunar, Bekman, \& Cemalcılar, 2004). In order to carry out early interventions appropriately, screening, 
diagnosis and evaluation must be done systematically. Evaluations can be carried out by systematic interviews and collection of all information obtained through formal and informal evaluation means applied (McConnell, 2000).

The classroom teacher takes the necessary physical and educational precautions for the child suspected of having special needs by receiving support from the school counselor and school administration (Gürsel, 2003). If these precautions are inadequate, a report including all the precautions taken is prepared and the medical diagnosis process for the child is initiated (Gürsel, 2003; Aksoy, 2016). In Turkey, in order to benefit from their legal rights individuals with disabilities need to have a medical diagnosis (Aksoy, 2016). In addition to medical diagnosis, educational diagnosis is required to determine the educational needs of the child and to prepare an individualized education program (Gürsel, 2003). Educational diagnosis is a process involving the determination of the child's characteristics in all developmental areas, the qualifications in the academic discipline fields and the educational needs and the decision to receive special education in the least restrictive educational environment for him or her (Milli Eğitim Bakanlığı, 2006).

In general, screening and diagnosis works in Turkey is carried out using standardized tests for which norm studies are conducted. These tests are valid and reliable means for formal measurement (Özgüven, 1994). There are many means that are used to assess children in their various characteristics. The most common ones are the developmental screening tests such as Denver, Bayley, Portage Checklist, and intelligence tests such as Stanford-Binet, and Wechsler Intelligence Scale for Children (WISC). Developmental screening tests are used to determine the risks associated with an impairment that may affect children's learning abilities. With this type of testing, children's cognitive, social, language and motor skills are measured and compared with the norm to determine whether they exhibit these skills at an appropriate level for their age. The intelligence tests, are diagnostic tools that are used to determine the child's general intelligence level, including verbal and performance-based measures, such as vocabulary, number sequences, arithmetic and image editing (Akman, 2016). The scores obtained from the intelligence tests and the information obtained from other formal and informal assessment tools are evaluated together to determine the type of disability and the degree of impact that the child has.

The evaluation process has a critical importance for infants and children with developmental disability or are at risk. This process is done in a certain order in Turkey, but it is known that there are many problems. Avcıoglu (2012) tried in his study to identify the views of RAM managers about the difficulties they face in the process of diagnosis, placement-monitoring, IEP preparation and inclusion. The results of the research demonstrate that in every process mentioned above there is inadequacy of the number of qualified personnel, lack of general screening programs for early diagnosis, lack of proper settings for the evaluation processes in the Guidance and Research Centers (RAM), lack of updated diagnostic and evaluation tools and lack of sufficient guidance to the families. The outcomes of another research by Diken et al. (2012) show that a systematic and comprehensive evaluation process in early childhood is not monitored in Turkey. In addition, there is no model where early intervention and special education services are provided for children with disabilities or children at risk and their families. In Turkey, especially to improve the effectiveness of early intervention in special education, the evaluation process should be carried out regularly and systematically by increasing the quality. 


\section{Türkiye’de Özel Eğitim Alanında Değerlendirme Süreci}

Millî Eğitim Bakanlı̆ı̆'nın 2018 yılında güncellediği Özel Eğitim Hizmetleri Yönetmeliği'ne (2018) göre özel eğitime gereksinim duyan birey "bireysel ve gelişim özellikleri ile eğitim yeterlilikleri açısından akranlarından anlamlı düzeyde farklılık gösteren birey" olarak tanımlanmaktadır. Özel eğitim gerektiren bireyler duyusal, duygusal ve eğitim gereksinimleri açısından desteğe gereksinim duymaktadır. 573 sayılı Özel Eğitim Hakkında KHK'ye (Milli Eğitim Bakanlığı, 1997) göre özel eğitime erken başlanılması gerekmektedir. Erken dönemde yapılan müdahaleler ve alınan önlemler ile ileride yaşanacak gelişimsel ve akademik yetersizliklerin önüne geçilebileceği belirtilmektedir (Erdil, 2010; Çakıroğlu, 2016). Erken eğitime başlayabilmek için ise bireyin değerlendirilmesi ve gereksinim duyduğu hizmetlerin belirlenmesi gerekir. Bu amaçla bireyin gelişiminin izlenmesi, risk grubunda olanların belirlenmesi, gerekli önlemlerin alınması ve gereksinim duyulan müdahale programlarının hazırlanması için çeşitli türde değerlendirmeler yapılmaktadır (Sucuoğlu, 2012). Bireyin değerlendirilmesi doğum öncesi dönemde başlamaktadır ve bebek yeni doğduğunda ve doğum sonrasında Sağlık Bakanlığı'nın ulusal yeni doğan tarama programları uygulanmaktadır. Genellikle çocuktaki gelişimsel yetersizlik, sağık kuruluşlarında yapılan kontrollerde fark edilmektedir. Bu dönemde gelişimsel yetersizliği belirlenemeyen çocuklar için daha sonra erken çocukluk ve okul döneminde çeşitli tarama ve değerlendirme çalışmaları yapılmaktadır (Tekin-iftar, 2011; Yüreğir, Büyükkurt, Koç ve Pazarbaşı, 2012; Özaltun, Güler ve Şengelen, 2015).

Değerlendirme sürecinin ilk basamağı olan tarama, yetersizliği olan ya da yetersizliği olduğundan şüphelenilen bireylerin erken dönemde belirlenmesi ve izlenmesi için kullanılan süreçtir. Tarama, problemlere farkındalık oluşturmakta ve potansiyel problemlerin erken dönemde tanılanmasına olanak sağlamaktadır (Gürsel, 2010). Özel Eğitim Hizmetleri Yönetmeliği (2018) değerlendirmenin bir diğer basamağı olan tanılamayı, uygun ortamlarda, bireyin özelliklerine uygun ölçme araçlarıyla yapılan ve sonucunda özel eğitime gereksinim duyduğu belirlenen bireylerin uygun eğitim ortamlarına yönlendirildiği bir süreç olarak açıklamaktadır. Tanılama tıbbi ve eğitsel tanılama olmak üzere iki şekilde yapılabilir. Tıbbi tanılamada çocuğun yetersizliği olup olmadığı ve yetersizliğe neden olan zedelenmenin yeri, derecesi, zedelenmeye yol açan etmenler gibi özellikler belirlenir. Eğitsel tanılamada ise bireyin tüm gelişim ve disiplin alanlarındaki özelliklerine bakılmaktadır (Baykoç-Dönmez, 2011). Türkiye'de eğitsel değerlendirme Millî Eğitim Bakanlığı'na bağı Rehberlik ve Araştırma Merkezleri (RAM) tarafindan yapılmaktadır (Diken, 2011).

Alanyazın incelendiğinde tarama ve tanılama çalışmalarının doğum öncesi dönemden başlayıp ileri dönem okul yıllarına kadar yapıldığı görülmektedir. Derleme makalesi olarak hazırlanan bu çalışmanın amacı, ülkemizde doğum öncesi ve doğum sonrası dönemlerde nasıl ve hangi araçlarla değerlendirme yapıldığını ortaya koymaktır. Çalışmanın, özel gereksinimi olan çocukların ailelerine, öğretmenlere ve bu alanda çalışan uzmanlara yol gösterici olacağı düşünülmektedir.

\section{Doğum Öncesi Dönemde Tarama ve Tanılama}

Hamilelik sürecinin başlamasıyla anne adayının sağlığının belirlenmesi için rutin kontroller gerçekleştirilir (Tekin-iftar, 2011). Doğum öncesi tarama, hamileliğin erken dönemlerinde çeşitli yöntemlerle alınan fetüse (gebeliğin üçüncü ayından doğuma kadar olan dönemde anne karnındaki canlı) ait örneklerin moleküler ve biyokimyasal yöntemlerle incelenerek genetik hastalıkların tanılanması işlemidir (Lo ve Chiu, 2007). Yapılan bu incelemeler sonrasında doğum öncesinde zihin yetersizliğine neden olabilecek kalıtsal bozuklukları ve nöral tüp defektleri (beyin ve omuriliğin oluşumda ortaya çıkan gelişimsel bozukluk) açısından risk altında olan bireyleri erken dönemde belirlemek mümkün olmaktadır. Aynı zamanda doğum öncesi tarama testleri, riskli gebeliklerde mümkünse doğum öncesi olası tedavi, doğum sonrası gereken önlem ve tedavilerin planlanması ve yasal süre geçmeden gebeliğin sonlandırılması firsatı sağlamaktadır (Yüreğir, Büyükkurt, Koç ve Pazarbaşı, 2012).

Tablo 1. Doğum öncesi tarama ve tanılama testleri

\begin{tabular}{ll}
\hline Invaziv Olmayan Testler (Tarama Testleri) & Invaziv Testler (Tanılama Testleri) \\
\hline 1.Fetal görüntüleme & 1.Fetal görüntüleme \\
Fetal ultrasonografik değerlendirme & Fetoskopi \\
Fetal ekokardiyografi & Embriyoskopi \\
Manyetik rezonans görüntüleme & 2.Fetal doku örneklerinde kromozom analizi veya moleküler incelemeler \\
Röntgenogram & Amniyosentez \\
2.Biyokimyasal tarama testleri & Koryon villus doku örneklemesi \\
Ikili tarama testi & Kordosentez \\
Üçlü tarama testi & Kas, karaciğer, böbrek gibi organ biyopsileri \\
Dörtlü tarama testi & \\
3.Maternal (Anne) kan örneğinde fetal hücrelerin analizi & \\
\hline
\end{tabular}

Kaynak: Yüreğir, Büyükkurt, Koç ve Pazarbaşı, 2012

Doğum öncesi yapılan testler tarama ve tanılama testleri olmak üzere ikiye ayrılmaktadır (Tekin-iftar, 2011). Tarama

| Kastamonu Eğitim Dergisi, 27(6), 2019| 
testleri, fetal görüntüleme ve anneden alınan kan örneğiyle yapılan biyokimyasal testleri içermektedir. Bu testler yüksek risk grubunda olan bebeklerin belirlenmesi amacıyla kullanılmaktadır. Tarama testleri sadece risk grubunda olan bebekleri belirlerken (Ergün, 2007), tanılama testleri kesin tanı koymada yardımcı olmaktadır (Sürmeliler, 2005; Tekin-iftar, 2011). Tablo 1'de doğum öncesi tarama ve tanılama testlerine yer verilmektedir.

\section{Yenidoğan ve Doğum Sonrası Tarama ve Tanılama}

Doğum sonrası dönem insan hayatında önemli ve riskli bir dönemdir (Ergün, 2007). Bebek dokuz ay boyunca anne rahminde büyüyüp geliştikten sonra dışarı çıkar ve yeni ortama uyum sağlamak durumundadır (Ergün, 2007). Bireyin dünyaya gözlerini açmasından sonra şüphelenilen tüm vakalarda ve ailede herhangi bir yetersizlik türü bulunanlarda kan ve idrar incelemeleri gerçekleştirilir. Farklı gelişim alanları açısından risk grubunda bulunan bebekleri belirlemede bazı gösterge ve incelemelere başvurulmaktadır. Bu araçların temel amacı, erken dönemde görülebilecek yetersizlikleri belirlemek, sistematik izleme sağlamak ve gerekli durumlarda eğitim hizmetlerine yönlendirilmektir (Alak, 2016).

Sağlık Bakanlığı, ülkemizde erken tarama ve tanılama amacıyla tüm bebeklere, Yenidoğan Tarama Programı, Yenidoğan İşitme Taraması Programı ve Gelişimsel Kalça Displazisi Erken Tanı ve Tedavi Programı uygulamaktadır (Bolat ve Genç, 2012; Özaltun, Güler ve Şengelen, 2015). Yenidoğan Tarama Programında, topuktan alınan kan örneği ile konjenital hipotiroidi, fenilketonüri, biyotinidaz eksikliği ve kistik fibrozis taramaları yapılmaktadır (Üstü ve Uğurlu, 2016). Konjenital Hipotiroidi, tiroit bezinin az çalışmasından kaynaklanan ve zekâ geriliğine neden olan önlenebilir bir durumdur. Görülme sıklığı yaklaşık 1/4000'dir. Topuk kanı alınarak tanı konur ve tedaviye erken başlanmasıyla zekâ geriliği önlenebilir (Şirin ve diğ., 2015). Fenilketonüri (Phenylketonuria- PKU), proteinli besinlerde bulunan fenilalanin adlı bir amino asidin metabolize edilememesi sonucu organlarda birikmesine neden olan bir durumdur. Zekâ geriliğine neden olur. İki yaşına kadar ortalama 50 IQ'ya kadar (ağır zekâ geriliği) düşüş yaşanır. Uygulanan diyet tedavisiyle zekâ geriliği önlenebilir. Tedavi yaşam boyu sürdürülmelidir (Zerjav Tansek et al., 2015). Biyotinidaz eksikliği, bebeklerde erken dönemde nöbetlere, enfeksiyonlara ve saç kaybına yol açmaktadır. Tedavi edilmezse görme kaybına, işitme kaybına, zekâ geriliğine hatta ölüme yol açabilir. Biyotinidaz eksikliğinin Türkiye'de görülme sıklığı 1/11000'dir ve bu rakam dünya ortalamasının çok üstündedir. B7 vitamini takviyesiyle tedavi edilir (Wolf, 2015). Kistik fibrozis, başta akciğerler olmak üzere birçok organın işlevini bozan kalıtımsal bir hastalıktır. Bebekte yapılan test pozitif sonuçlanırsa, göğüs hastalıkları ve/veya gastroenteroloji kliniğine sevk edilir. Kistik fibrozis olan hamile anne ise amniyosentez bakımından değerlendirilmelidir. Erken başlanan tedavi ile organlarda oluşan hasar önlenebilir veya geciktirilebilir. Ocak 2015'ten başlayarak Yenidoğan Tarama Programına alınmıştır.

Yenidoğan İşitme Tarama Programı doğrultusunda ülkemizde doğan her bebeğe doğumdan sonra işitme testi yapılmaktadır. Ülkemizde doğan her bin bebekten 2-3'ünde işitme kaybı görülmektedir. İşitme kaybı erken tanılanmaz ve rehabilitasyon programına başlanmazsa işitme yetersizliği olan bireylerin sadece dil ve konuşma gelişimlerinde değil aynı zamanda sosyal ve psikolojik gelişimlerinde de sorunlar görülebilir. Tanılama amacıyla doğum sonrası 24 saat geçiren bebeğe işitme testi uygulanır. İ̧itme kaybı görüldüğü durumda uygun işitme cihazı takılmalıdır (Bolat ve Genç, 2012).

Gelişimsel Kalça Displazisi (kalça çıkı̆̆ı) Taraması, yenidoğan tüm bebeklere uygulanmaktadır. Türkiye'de görülme sıklığı 1/1000'dir. Erken tanı ve tedavi ile tamamen ortadan kaldırılabilir (GKD Tarama Programı, 2013). Erken tanı için bir aylık bebekler aile hekimleri tarafindan muayene edilir ve gerek görüldüğünde ortopedi kliniğine sevk edilir (Özaltun, Güler ve Şengelen, 2015).

Bunun dışında doğum sonrası tarama için kullanılan incelemeler arasında kan testleri (fenilketonüri gibi metabolik bozukluklar), kan biyokimyası testleri (kretenizm, raşitizm ve sarılık), kan antikor titreleri (enfeksiyonlar), kromozom analizi (down sendromu için), nörodavranışsal değerlendirmeler, elektroensefalografi- EEG (nöbet bozukluğu), görüş keskinliği, fundus (gözün iç tarafi) incelemesi, retinoskopi (göz bozukluğu), timpanogram (işitme testi), BERA (işitme sorunları), ultrasonografi, bilgisayarlı tomografi ve Manyetik Rezonans Görüntüleme-MRG (serebral palsinin belirlenmesi için) bulunmaktadır (Alak, 2016).

\section{Erken Çocukluk ve Okul Dönemi Çocuklarında Tarama, Tanılama ve Değerlendirme}

Özel eğitimde erken müdahalenin önemi birçok araşttrmacı tarafindan vurgulanmaktadır (Birkan, 2002a; Kağıtçıbaşı, Sunar, Bekman ve Cemalcılar, 2004). Erken müdahalenin sağlıklı bir şekilde yürütülebilmesi için tarama, tanılama ve değerlendirmenin sistematik olarak yapılması gerekmektedir. Ülkemizde özel eğitim ile ilgili mevzuatta tanılama ve değerlendirmenin erken yaşta ve her aşamada yapılması gerektiği ile ilgili yasal düzenlemeler bulunmaktadır (MEB, 1997).

Çocuğun erken yaşta değerlendirilmesi uygulanacak olan eğitim programının belirlenmesine yol göstermektedir (Birkan, 2002b). Değerlendirmeler, sistematik bir şekilde yapılan görüşmelerle, uygulanan formal ve informal araçlarla elde edilen tüm kayıtlı bilgilerin toplanması ile yapılabilmektedir (McConnell, 2000). 
Okul döneminde özel gereksinimli olduğu düşünülen çocuğun sınıf öğretmeni rehberlik servisinin ve okul yönetiminin desteğini alarak sınıf içi ve okul içi gerekli fiziksel ve eğitsel önlemleri alır (Gürsel, 2003). Bu çalışmalar yetersiz kalırsa yapılan işlemler raporlaştırıır ve çocuk için öncelikle tıbbi tanılama süreci başlatılır (Aksoy, 2016; Gürsel, 2003). Tıbbi tanılama işlemi psikometrik ölçümleri içeren tobbi bir süreçtir. Ülkemizde özel gereksinimli bireylerin yasal haklarından yararlanabilmeleri için tıbbi tanılama gerekmektedir (Aksoy, 2016). Tıbbi tanılama ile çocuğun yetersizlik türünün belirlenmesinin yanında yetersizlikten etkilenme derecesi ve olası nedenleri hakkında bilgi edinilebilir ancak tıbbi tanılama çocuğun eğitsel gereksinimlerini ve intiyaç duyduğu eğitim ortamlarını belirlemede yetersiz kalmaktadır (Aksoy, 2016). Çocuğun eğitim gereksinimlerini belirlemek ve bireyselleştirilmiş eğitim programı hazırlamak için tıbbi tanılamanın yanında eğitsel tanılama yapılması gerekmektedir (Gürsel, 2003). Özel Eğitim Hizmetleri Yönetmeliği'ne (2018) göre eğitsel değerlendirme ve tanılama, "bireyin tüm gelişim alanlarındaki özellikleri ve akademik disiplin alanlarındaki yeterlilikleri ile eğitim intiyaçları birlikte değerlendirilerek eğitimin her tür ve kademesindeki geçişlerde yapılır". Eğitsel değerlendirme sürecinde RAM’larda "Özel Eğitim Değerlendirme Kurulu” öğrencinin özel eğitim hizmetlerinden yararlanmayı gerektirecek bir yetersizliği olup olmadığını belirlemeye çalışır (Çuhadar, 2017).

Ülkemizde tanılama çalışmaları genellikle standartlaştrılmış ve zekâ testi denilen araçlarla yapılmaktadır. Bu testler geçerlik, güvenirlik ve norm çalışmalarının yapıldığı formal testlerden oluşmaktadır (Özgüven, 1994). Yetersizliği olan bireylerin tanılanmasında ve sınıflandırılmasında zekâ testleri günümüzde yaygın olarak kullanılmaktadır (Kırcaali-iftar, 2013). Zekâ testleri genel olarak kelime bilgisi, sayı dizileri, aritmetik ve resim düzenleme gibi bir takım sözel ve performansa dayalı ölçümleri içeren ve çocuğun genel zekâ seviyesinin belirlenmesi amacıyla kullanılan tanılama araçlarıdır (Akman, 2016). Ülkemizde erken çocukluk ve okul döneminde tarama ve tanılama için kullanılan formal değerlendirme araçları şöyle sıralanabilir:

Denver Gelişimsel Tarama Testi: Test, 0-6 yaş çocuklar için kullanılmaktadır. Kişisel-sosyal, ince motor, dil, kaba motor olmak üzere dört alt testi bulunmaktadır. Türkçe çevirisi 1987 yılında Yalaz ve Epir tarafindan yayımlanmıştır. Çocuğu gözlemleyerek uygulanır. Gözlenmesi kolay olmayan maddeler aile iş birliğiyle değerlendirilebilir (Kırcaali-iftar, 2013).

Bayley Bebek Gelişimi Ölçeği (Bayley-III, 2006): Bebeklerde ve ağır derecede zihin yetersizliği bulunan bireylerde, zekâ testi yerine uygulanabilmektedir. Dünyada en sık kullanılan gelişim ölçeklerinden biridir (Kırcaali-iftar, 2013). Zihinsel, motor ve davranış gelişimi gibi geniş bir kapsam alanına sahiptir. Verilen tablodan çocuğun zihinsel ve motor yaşı tahmin edilebilir. Test, aile tarafindan yapılmaya uygundur (Baykoç Dönmez, 2011).

Portage Kontrol Listesi: Portage projesi 1969 yılında ABD'de geliştirilmiştir ve proje kapsamında geliştirilen kontrol listesi 1972 yılından bu yana dünyanın birçok ülkesinde kullanılan bir test haline gelmiştir. Ülkemizde 1993 yılında kullanılmaya başlanmıştır. Portage Erken Çocukluk Dönemi Eğitim Programı Kontrol Listeleri alt yaş bölümünden ve altı gelişim alanından oluşan 691 maddeden oluşmaktadır. Bu araçla çocuğun bilişsel, duyuşsal, öz bakım, motor, sosyal ve dil becerileri ölçülmektedir (Birkan, 2002a; Çağdaş ve Yıldız, 2003).

Gazi Erken Gelişimi Değerlendirme Aracı: Temel, Ersoy, Avcı ve Turla tarafindan geliştirilmiştir. Test 15 gün ile 72 ay arası Türk çocuklarına uygulanan bireysel bir testtir. Çocuklarda gelişimsel özelliklerin değerlendirilmesi ve risk altında olduğu düşünülen çocukların daha üst düzey değerlendirme için yönlendirilmesi amacıyla kullanılmaktadır. Test, çocukların sosyal-duygusal, psikomotor ve bilişsel gelişim alanlarını değerlendirmektedir. Gerektiğinde ebeveyn fikirlerine danışılabilir (Sucuoğlu, 2012).

Erken Çocukluk Dönemi Otizm Kontrol Listesi: Erken Çocukluk Dönemi Otizm Kontrol Listesi, 18-30/36 aylık olan ve otizm şüphesi taşıyan çocuklarda otizm belirtilerini belirlemek için tasarlanmış bir tarama ölçeğidir. Bu kontrol listesi 23 maddeden oluşmaktadır ve genelde birincil bakıcı tarafindan doldurulmaktadır. Ancak, Türkiye'de yapılan çalışmada ölçeğin eğitilmiş sağlık çalışanlarının (psikolog, hemşire, vb.) desteği ile uygulanmasının daha doğru olabileceği belirlenmiştir (Kara, Mukaddes, Altınkaya, Güntepe, Gökçay ve Özmen, 2014).

Ankara Gelişim Tarama Envanteri (AGTE): Işık, Savaşır ve Erol tarafindan Hacettepe Üniversitesinde 1992 yılında geliştirilmiştir. Envanter 2005 yılında genişletilmiş 3. baskısıyla yayımlanmıştır. Dil-bilişsel, ince motor, kaba motor, sosyal beceri-öz bakım olmak üzere dört alt testten oluşmaktadır. Test 0-6 yaş grubuna uygulanabilmektedir. Birincil bakıcıya sorularak uygulanmaktadır (Kırcaali-iftar, 2013).

Stanford-Binet Zekâ Ölçeği: Akıcı akıl yürütme, bilgi, nicel akıl yürütme, görsel-mekânsal bilgi işleme ve çalışma belleği alanlarında değerlendirme yapmaktadır. Ölçek, 2-18 yaş arasındaki bireylere uygulanabilmektedir. Sözel ve performansa dayalı bir ölçek türüdür. Türkçe çevirisi 1987 yılında Refia Uğurel-Şemin tarafindan yapılmıştır. (Eripek, 2009).

Wechsler Çocuklar İçin Zekâ Ölçeği-4 (WISC IV, 2003): Sözel anlama-benzerlikler, sözcük dağarcığı, anlama, algısal akıl yürütme-matris akıl yürütme, blok desenleme, resim kavramları, çalıșan bellek-harf-sayı sıralama, sayı dizisi, bilgi | Kastamonu Eğitim Dergisi, 27(6), 2019| 
işleme hızı- sembol araştırma ve kodlama alanlarında değerlendirme yapmaktadır. Ölçek, 6-16 yaş arasındaki bireylere uygulanabilmektedir. Sözel ve performansa dayalı bir ölçek türüdür (Kırcaali-iftar, 2013).

Cattell'in Kültürden Arındırılmış Zekâ Testi: Bu test, 6 ile 20 yaş arası bireylerin zekâ puanlarını belirlemek için uygulanan bir grup zekâ testidir. Testin uygulama süresi 25 dakikadır. Genellikle tarama amacıyla uygulanan bu test araştrmacılar tarafindan zekânın ölçülebilmesi için geliştirilen en iyi grup zekâ testi olarak tanımlanmıştır (Fernández- Ballesteros ve Colom, 2004). Testin en iyi grup zekâ testi olarak tanımlanmasının nedenleri, uygulanmasının kolay olması, zaman tasarrufu sağlaması, materyallerin kolayca elde edilebilmesi ve kültürel özelliklerden arınmış olmasıdır (Öner, 1994). Test, serileri tamamlama, tasnif, sınıflandırma ve yerleştirme alt testlerinden oluşmaktadır. Her alt testin uygulama yönergesi değişmektedir (Özgüven, 1994).

Raven'in Standart Progresif Matrisler Testi (RSPM): Bu test her yaş grubundaki bireye rahatlıkla uygulanabilecek bir grup zekâ testidir. Test A, B, C, D ve E olmak üzere beş bölümden oluşmaktadır. Her bölümde 12 tane alt madde vardır. Maddeler hem A'dan E'ye doğru hem de her bölümün alttnda yer alan 12 alt madde kendi içerisinde 1'den 12'ye doğru güçleşmektedir. Test bu açıdan giderek zorlaşan bir yapıdadır (Zaiman, 2001). Test sözel becerileri ölçmekten tamamen arındırılmıştr. Bu yüzden her ırktan, her yaştan, her sosyo-ekonomik düzeyden bireyleri eşit olarak ölçebilmektedir. Testte herhangi bir süre sınırlaması yoktur (Raven ve Summers, 1990).

Bilişsel Değerlendirme Sistemi (CAS, 1997): Planlama-sayı eşleme, planlı kodlar, dikkat-ifadesel dikkat, sayı bulma, eş zamanlılık-sözel olmayan matrisler, sözel mekânsal ilişkiler, ardışıklık-sözcük dizileri ve cümle tekrarları alanlarında değerlendirme yapmaktadır. Ölçek, 5-17 yaş arasındaki bireylere uygulanabilmektedir. Sözel ve performansa dayalı bir ölçek türüdür. Türkiye'de çeşitli yaş düzeylerinde norm çalışmaları yapılmıştır (Kaner, Bayraklı, Diken ve Çelik, 2012).

Leiter Uluslararası Performans Testi- Yenilenmiş (LIPS-R, 1997): Akıcı zekâ, dikkat ve bellek alanlarında değerlendirme yapmaktadır. Ölçek, 2-21 yaş arası bireylere uygulanabilmektedir. Performansa dayalı bir ölçek türüdür. İşitme ve konuşma problemi olan çocukların zihinsel performanslarını belirlemek için kullanılmaktadır. Ülkemizde revize edilmemiş hali olan 1979 versiyonu kullanılmaktadır (Kırcaali-iftar, 2013).

Çocuklar İ̧̧in Kaufman Değerlendirme Bataryası-2 (2004): Ardışık bilgi işleme, eş zamanlı bilgi işleme, öğrenme, planlama ve bilgi alanlarında değerlendirme yapmaktadır. Ölçek, 3-18 yaş arası bireylere uygulanabilmektedir. Sözel ve performansa dayalı bir ölçek türüdür. Millî Eğitim Bakanlığı tarafindan 2004 yılında norm çalışması yapılmıştır (Alak, 2016).

Porteus Labirentleri Testi: Sonrayı ön görebilme ve temkinli davranma alanlarında değerlendirme yapmaktadır. Ölçek, 3-14 yaş arası bireylere uygulanabilmektedir. Performansa dayalı bir ölçek türüdür. Türkçeye çevirisi 1974 yılında Beglan Toğrol tarafindan yapılmıştı (Kaner, Bayraklı, Diken ve Çelik, 2012).

Kohs Küpleri Testi: Zaman yönetimi ve görsel algı alanlarında değerlendirme yapmaktadır. Ölçek 3-19 yaş arası bireylere uygulanabilmektedir. Performansa dayalı bir ölçek türüdür. Wechsler Yetişkinler İçin Zekâ Ölçeği ve Palmer gibi kapsamlı zekâ testleri takımlarının içinde de yer almaktadır (Kırcaali-iftar, 2013).

Goodenough-Harris İnsan Resmi Çizme Testi: Çocuğun çizdiği insan resminin, yanıt anahtarına göre değerlendirilmesini kapsamaktadır. Ölçek, okul öncesi dönemden 15 yaşa kadar olan bireylere uygulanabilmektedir. Performansa dayalı bir ölçek türüdür. Perin Uçman tarafindan 1971 yılında Türkçeye çevrilmiştir. Ölçeğin norm çalışması bulunmaktadır (Kırcaali-iftar, 2013).

Vineland Uyum Davranış Ölçeği (VABS-II, 2005): En eski ve günümüzde en yaygın olarak kullanılan ölçeklerden biridir. Doğumdan yetişkinliğe kadar süreci kapsayan, kişisel ve toplumsal becerileri değerlendiren bir ölçme aracıdır. Ölçekte iletişim, günlük yaşam, sosyalleşme ve devinsel beceriler ile uyumsal davranışlar değerlendirilmektedir (Kırcaali-iftar, 2013).

Uyumsal Davranış Değerlendirme Sistemi (ABAS-II, 2003): Bu ölçek doğumdan itibaren kullanılabilen ve en son geliştirilen ölçeklerden biridir. Ölçek sosyal, kavramsal ve pratik becerileri kapsayacak şekilde üç alanda yer alan on özel uyumsal beceriyi değerlendirmektedir. Ölçekte, bireyin birincil bakıcılarından alınan bilgilere göre değerlendirme yapılmaktadır (Kırcaali-iftar, 2013; Alak, 2016).

Peabody Resim-Kelime Testi (PPVT, 1965): Dunn tarafindan geliştirilen ve 1974 yılında Türkçeye uyarlanan bu test ülkemizde yaygın olarak kullanılmaktadır. Norm çalışması yapılmıştı. Test 2-12 yaş arasındaki çocuklara yöneliktir (Kırcaali-iftar,2013). Testin amacı, sözcükleri ve sözel olmayan alıcı dili ölçmektir. Test, verilen sözcükler için resim tanımayı içerir (Baykoç-Dönmez, 2011). 
Bender-Gestalt Görsel Motor Testi (Bender-Gestalt, 2003): Görsel-devinsel becerileri değerlendirmede kullanılır. Test 5-10 yaş arasındaki bireylere uygulanmaktadır. Çocuklardan geometrik şekilleri bakarak ve bakmadan çizmeleri beklenmektedir (Kırcaali-iftar, 2013).

Anadolu-Sak Zekâ Ölçeği (ASIS): Anadolu Üniversitesi ve Millî Eğitim Bakanlığı destekleriyle Üstün Yetenekliler Eğitimi Araştırma ve Uygulama Merkezi (ÜYEP) tarafindan 2015-2017 yılları arasında geliştirilmiştir. Türkiye'nin ilk yerli zekâ ölçeğidir. Genel zekâyı ve zekâyı oluşturan ana bileşenleri ölçmeyi amaçlayan bir testtir. Yedi alt testten oluşan test bireysel olarak uygulanmaktadır. Genel zekâ endeksi, sözel potansiyel endeksi, görsel potansiyel endeksi, bellek kapasitesi endeksi, sözel IQ, görsel IQ, sözel kısa süreli bellek endeksi ve görsel uzamsal işleyen bellek endeksi olmak üzere sekiz farklı performansı ölçmektedir (Projeiq, 2015).

Tablo 2. Erken çocukluk ve okul döneminde kullanılan tarama ve tanılama araçları

\begin{tabular}{|c|c|c|c|c|c|c|}
\hline \multirow[b]{2}{*}{ Ölçek/Araç } & \multirow[b]{2}{*}{ Yaş } & \multicolumn{5}{|c|}{ Gelişim Alanları } \\
\hline & & Bilişsel & $\begin{array}{c}\text { Dil } \\
\text { İletişim }\end{array}$ & Motor & $\begin{array}{c}\text { Öz } \\
\text { Bakım }\end{array}$ & $\begin{array}{c}\text { Sosyal } \\
\text { Duyusal }\end{array}$ \\
\hline Denver Gelişimsel Tarama Testi & $0-6$ & & $x$ & $x$ & & $x$ \\
\hline Bayley Bebek Gelişimi Ölçeği (Bayley-III) & $0-3.5$ & $x$ & & $x$ & & \\
\hline Portage Kontrol Listesi & $0-6$ & $\mathrm{X}$ & & & & \\
\hline Gazi Erken Gelişimi Değerlendirme Aracı (GEÇDA) & $0-6$ & $x$ & & $x$ & $\mathrm{x}$ & $x$ \\
\hline Erken Çocukluk Otizmi Kontrol Listesi & $1,5-3$ & & & & & \\
\hline Ankara Gelişim Tarama Envanteri (AGTE) & $0-6$ & & $x$ & $x$ & $\mathrm{x}$ & $x$ \\
\hline Stanford-Binet Zekâ Ölçeği (SB-5) & $2-18$ & $x$ & & & & \\
\hline Wechsler Çocuklar İçin Zekâ Ölçeği-4 (WISC IV) & $6-16$ & $x$ & & & & \\
\hline Cattell'in Kültürden Arındırılmış Zekâ Testi & $6-20$ & $\mathrm{X}$ & & & & \\
\hline Raven'in Standart Progresif Matrisler Testi (RSPM) & $0+$ & $x$ & & & & \\
\hline Bilişsel Değerlendirme Sistemi (CAS) & $5-17$ & $x$ & & & & \\
\hline Leiter Uluslararası Performans Testi- Yenilenmiş (LIPS-R) & $2-21$ & $x$ & & & & \\
\hline Çocuklar İçin Kaufman Değerlendirme Bataryası-2 & $3-18$ & $x$ & & & & \\
\hline Porteus Labirentler Testi & $3-14$ & $x$ & & & & \\
\hline Kohs Küpleri Testi & $3-19$ & $x$ & & & & \\
\hline Goodenough-Harris İnsan Resmi Çizme Testi & $3-15$ & $x$ & & & & \\
\hline Vineland Uyum Davranış Ölçeği (VABS-II) & $0-19$ & & & & $x$ & $\mathrm{X}$ \\
\hline Uyumsal Davranış Değerlendirme Sistemi (ABAS-II) & $0+$ & & & & & $x$ \\
\hline Peabody Resim-Kelime Testi (PPVT) & $2-12$ & & $x$ & & & \\
\hline Bender-Gestalt Görsel Motor Testi (Bender-Gestalt) & $5-10$ & & & $\mathrm{X}$ & & \\
\hline Anadolu Sak Zekâ Ölçeği (ASIS) & $4-12$ & $x$ & & & & \\
\hline
\end{tabular}

Yukarıda açıklanan ölçekler Tablo 2'de verilmiştir. Araştırmaya Türkiye'de kullanılan 21 tarama ve tanılama aracı dahil edilmiştir. Tablo, kullanılan ölçeklerin kullanılabileceği yaş ve gelişim alanlarına göre özet bilgi içermektedir. Türkiye'de kullanılan ölçek ve değerlendirme araçları 0-21 yaş arasını kapsamaktadır. Ancak tabloda verilen iki ölçek (Raven'in Standart Progresif Matrisler Testi ve Uyumsal Davranış Değerlendirme Sistemi) tüm yaştaki bireylere uygulanabilmektedir. Türkiye'de kullanılan ölçek ve değerlendirme araçları bilişsel, dil iletişim, motor, öz bakım ve sosyal duygusal gelişim alanlarını ölçmektedir. Kullanılan ölçek ve değerlendirme araçları incelendiğinde en çok bilişsel gelişim alanını, en az ise dil iletişim ve öz bakım becerilerini ölçmeye yönelik araçların bulunduğu görülmektedir.

\section{Sonuç ve Tartışma}

Bu çalışmada, ülkemizde, doğum öncesi dönemden okul dönemine kadar uygulanan tarama, tanılama ve değerlendirme çalışmaları ve bu çalışmalarda kullanılan ölçme ve değerlendirme araçlarının özellikleri ve kullanım amaçları tanıtımıştır. Doğum öncesi ve doğum sonrası yapılan tarama testleri ile risk grubunda olan çocuklar belirlenmekte, tanılama testleriyle de yetersizliğin kesin tanısı konulmaktadır. Sonraki aşamada yetersizliği bulunan çocuk için gerekli müdahale programları başlatılmaktadır. Bu müdahale programlarının erken başlatılmasıyla, yetersizliğin daha da ilerlemesi ya da bașka gelișim alanlarını olumsuz bir șekilde etkilemesi önlenebilmektedir.

| Kastamonu Eğitim Dergisi, 27(6), 2019| 
Okul öncesi ve okul döneminde yapılan değerlendirmeyle öğrencilerin fiziksel, davranışsal ve akademik özellikleri belirlenerek gerekli yasal ve eğitsel kararlar alınır. Gürsel ve Vuran (2010), öğrencilerin yetersizliğinin türü ve derecesinin belirlenmesindeki amaçları, (a) ailelerin ve çocukların haklarının korunması, (b) çocukların özel eğitim hizmetlerinden yararlanabilmesi için değerlendirmenin yasal zorunluluk olması ve (c) öğrencinin öğrenme gereksinimlerinin yanında yeterli ve yetersiz olduğu alanların ayrıntılı bir şekilde değerlendirilmesi olarak sıralamışlardır. Öğrencinin erken dönemde değerlendirilmesi ve tanılanması uygun eğitim hizmetlerinden erken yararlanmasını sağlamakta; uygulanan erken müdahale programları, ileride yaşanabilecek gelişimsel ve akademik yetersizlikleri en aza indirmede etkili olmaktadır.

Ülkemizde özel eğitime gereksinimi olan bireylerin tanılanması, eğitsel performanslarının alınması, uygun eğitim ortamlarına karar verilmesi ve öğrencilerin gelişmelerinin izlenmesi Rehberlik Araştırma Merkezleri (RAM) tarafindan gerçekleştirilmektedir. Ancak özel eğitime gereksinim duyduğu ya da risk altında olduğu düşünülen öğrencinin ayrıntılı değerlendirme için RAM'a gönderilmeden önce sınıfa uyum sağlaması ve herhangi bir tanı almadan genel eğitime devam etmesi amaçlanır. Bu amaçla okullarda gönderme öncesi sürecin yürütülmesi gerekmektedir. Alanyazın incelendiğinde elde edilen bulgulara göre gönderme öncesi süreç, öğrencinin sosyal kabulü üzerinde olumsuz etkileri olan etiketlemeyi ortadan kaldırmada oldukça kritik bir role sahiptir (Kirk, Gallagher, Coleman ve Anastasiow 2011). Araştrmalar, özel gereksinimli bireylere sistematik ve planlı şekilde uygulanan gönderme öncesi sürecin, ayrıntlı değerlendirilmelerine gerek kalmadan genel eğitim sınıfinda eğitimlerini sürdürmelerinde etkili olduğunu göstermektedir (Kargın, 2007; Kirk ve ark., 2011). Gönderme öncesi süreç sonunda sınıfa uyum sağlamada beklenen performansı gösteremeyen öğrenciler ayrıntılı değerlendirilmeleri amacıyla RAM'a gönderilmektedir. Öğrencilerin RAM'a gönderilmeleri için okullarda bir gönderme süreci başlatılmaktadır. Bu süreçte, öğrencinin ayrıntılı değerlendirmeye gönderilmesi için gereken çalışmalar yapılır. Örneğin öğrenci hakkında toplanan bilgiler ve yapılan uyarlamalar rapor haline getirilir (Kargın, 2007); yapılan tüm uyarlamalar ve destek çalışmalarına karşın öğrencinin sınıfa uyum sağlamakta zorlanması nedeniyle ayrıntlı değerlendirmeye gereksinim duyduğu açıklanır.

Alanyazındaki çalışmalara bakıldığında hem gönderme hem de ayrıntılı değerlendirme süreçlerine ilişkin sorunlar yaşandığı anlaşıımaktadır. Örneğin Özak, Vural ve Avcıoğlu (2008) tarafindan RAM müdürlerinin gönderme, tanılama ve değerlendirme hakkındaki görüşleri ve önerilerini belirlemek amacıyla yapılan çalışmada müdürlerin okul tarafindan gönderilen dosyalarda öğrenciye ilişkin yazılanların doğruluğundan şüphe duydukları ortaya çıkarılmıştır. Avcıoğlu (2012) bir başka araştırmasında RAM müdürlerinin tanılama, yerleştirme-izleme, BEP hazırlama ve kaynaştırma süreçlerinde karşılaştıkları zorluklar hakkındaki görüşlerini belirlemeye çalışmıştı. Araştırmanın sonucunda yukarıda ifade edilen her süreçte uzman personel sayısının yetersiz olması, erken tanılama için genel tarama programlarının hiç olmaması ya da yaygın olmaması, RAM'larda değerlendirmenin yapıldığı ortamların uygun şekilde düzenlenmemiş olması, tanılama ve değerlendirme araçlarının güncel olmaması ve aileye gerekli açıklamaların ya da yönlendirmelerin yapılmaması gibi sorunların yaşandığı ifade edilmiştir (Avcıoğlu, 2012). Diken ve ark. (2012) tarafindan yapılan bir araştırmada ise, ülkemizde erken çocukluk döneminde sistemli ve kapsamlı bir değerlendirme sürecinin izlenmediği, ayrıca yetersizliği olan ya da risk grubunda bulunan çocuklara ve ailelerine yönelik erken müdahale ve özel eğitim hizmetlerinin sunulduğu bir modelin bulunmadığı açıklanmıştı. Alanyazında ailelerin değerlendirme sürecine katılımıyla ilgili de araştırmalar yapıldığı görülmekte; bu araştırmalarda aile, öğretmen ve rehberlik servisinin işbirliği yapmasının değerlendirme sürecine olumlu etkileri olduğu ortaya konulmaktadır (Batu, 2008; Kargın, 2007; Taylor, Richards ve Brady, 2005).

Değerlendirme çalışmalarının erken dönemden başlayarak sistematik ve düzenli bir şekilde yapılması, her aşamada gereksinim duyulan hizmetin doğru ya da uygun olarak planlanmasına olanak tanımaktadır. Uygun yapılan değerlendirme ile ihtiyaca yönelik hazırlanan plan sayesinde hem zaman tasarrufu sağlanmakta hem de etkili müdahaleye mümkün olan en erken dönemde başlanmaktadır.

\section{Kaynakça}

Akman, B. (2016). Standardize testler. Ç. Dinçer (Ed.), Gelişimsel tanı ve değerlendirme yöntemleri içinde (s. 100-119). Eskişehir: Anadolu Üniversitesi Yayınları.

Aksoy, F. (2016). Özel gereksinimli bireylere sunulan hizmetler ve yasal haklar. V. Aksoy (Ed.), Özel eğitim içinde (s. 268-297). Ankara: Pegem Akademi.

Alak G. (2016). Zihin yetersizliği: tarama, tanılama ve değerlendirme. İ. H. Diken ve H. Bakkaloğlu (Eds.), Zihin yetersizliği ve otizm spektrum bozukluğu (s. 59-89). Ankara: Pegem Akademi.

Avcıoğlu, H. (2012). Rehberlik ve araştırma merkez (RAM) müdürlerinin tanılama, yerleştirme-izleme, bireyselleştirilmiş eğitim programı (BEP) geliştirme ve kaynaştırma uygulamasında karşılaşılan sorunlara ilişkin algıları. Kuram ve Uygulamada Eğitim Bilimleri, 12(3), 2009-2031.

Batu, S. (2008). Kaynaştırma desteği sağlama. Eripek, S. Özel Eğitim (Ed.). s. 21- 41. Eskişehir: Anadolu Üniversitesi Yayınları. 
Baykoç-Dönmez, N. (2011). Özel gereksinimli çocuklar ve özel eğitim. N. Baykoç Dönmez (Ed.), Özel gereksinimli çocuklar ve özel eğitim içinde (s. 19-27). Ankara: Eğiten Kitap.

Birkan, B. (2002a). Erken özel eğitim hizmetleri. Ankara Üniversitesi Eğitim Bilimleri Fakültesi Özel Eğitim Dergisi, 3(02).

Birkan, B. (2002b). Küçük adımlar kursunun gelişim geriliği olan çocuğa sahip annelerin küçük adımları uygulama becerilerini kazandırmalarına etkisi. Eskişehir: Anadolu Üniversitesi Yayınları.

Bolat, H. ve Genç, O. G. A. (2012). Türkiye ulusal yenidoğan işitme taraması programı: Tarihçesi ve prensipleri. Turkiye Klinikleri Journal of ENT Special Topics, 5(2), 11-14.

Çağdaş, A. ve Yıldız, F. Ü. (2003). Deneysel yaratıcılık programı’nın 4-5 yaş çocuklarının bilişsel gelişimine olan etkileri. Selçuk Üniversitesi Sosyal Bilimler Enstitüsü Dergisi, (10), 315-328.

Çakıroğlu, O. (2016). Özel eğitimde temel kavramlar. V. Aksoy (Ed.), Özel eğitim içinde (s. 1-19). Ankara: Pegem Akademi.

Diken, I. H. (2011). Erken tanılama ve erken eğitim. E. S. Batu (Ed.), 0-6 yaş arası down sendromlu çocuklar ve gelişimleri (2. Baskı) içinde (s. 371-384). Ankara: Kök Yayıncılık.

Diken, I., Bayhan, P., Turan, F., Sipal, F., Sucuoglu, B., Ceber-Bakkaloglu, H. et al. (2012). Early Childhood Intervention and Early Childhood Special Education in Turkey within the Scope of the Developmental System Approach. Infants and Young Children, 25(4), 346-353.

Erdil, Z. (2010). Sosyoekonomik olarak risk altında bulunan çocuklara yönelik erken müdahale programları ve akademik başarı ilişkisi. Sağlık Bilimleri Fakültesi Hemşirelik Dergisi, 72-78.

Ergün, P. (2007). Gebelerin Üçlü Tarama Testi ve Gebelikte Yapılan Diğer Testler Hakkındaki Bilgi Düzeyinin Ölçülmesi (Yüksek lisans tezi, Afyon Kocatepe Üniversitesi, Afyon).

Eripek, S. (2009). Zihinsel yetersizliği olan çocuklar. Ankara: Maya Akademi.

Fernández-Ballesteros, R. ve Colom, R. (2004). The psychology of intelligence in spain, In R. J. Sternberg (Ed.), International Handbook of Intelligence, (79-103). Cambridge, UK: Cambridge University Press.

Gürsel, O. (2003). Özel gereksinimi olan çocukları değerlendirme. O. Gürsel (Ed.), Bireyselleştirilmiş eğitim programlarının geliştirilmesi içinde (s. 45-53). Eskişehir: Anadolu Üniversitesi Yayınları.

Gürsel, O. (2010). Özel eğitimde değerlendirme. H.i. Diken (Ed.), Özel eğitim içinde (s. 29-58). Ankara: Pegem Akademi.

Gürsel, O. ve Vuran, S. (2010). Değerlendirme ve Bireyselleştirilmiş Eğitim Programlarını Geliştirme. H. I. Diken (Ed.), ilköğretimde Kaynaştırma içinde (s. 194-22). Ankara: Pegem Akademi.

İçke, S., ve Genç, R. E. Topuk kanı örneği ile yapılan ulusal yenidoğan tarama testleri ve önemi. The Journal of Pediatric Research, 4(4), 186-90.

Kağıtçıbaşı, Ç., Sunar, D., Bekman, S. ve Cemalcılar, Z. (2004). Erken müdahalenin erişkinlikte süren etkileri: Erken destek projesinin ikinci takip araştırmasının ön bulguları. İstanbul: Anne-Çocuk Eğitim Vakfi Yayınları.

Kaner, S., Bayraklı, H., Diken, H. İ. ve Çelik, S. (2012). Türkiye'de özel eğitim alanında geliştirilen ve uyarlanan ölçme araçları. Ankara: Maya Akademi.

Kara, B., Mukaddes, N. M., Altınkaya, I., Güntepe, D., Gökçay, G. ve Özmen, M. (2014). Using the Modified Checklist for Autism in Toddlers in a well-child clinic in Turkey: Adapting the screening method based on culture and setting. Autism, 18(3), $331-338$.

Kargın, T. (2007). Eğitsel Değerlendirme ve Bireyselleştirilmiş Eğitim Programı Hazırlama Süreci. Özel Eğitim Dergisi, 8(1), 1-17.

Kırcaali-iftar G. (2013). Zihin engellilerin değerlendirilmesi. Bülbin Sucuoğlu (Ed.), Zihin engelliler ve eğitimleri (s. 178-202). Ankara: Kök Yayıncılık.

Kirk, S., Gallagher, J. J., Coleman, M. R. ve Anastasiow, N. J. (2011). Educating exceptional children. Cengage Learning.

Lo, Y.D. ve Chiu, R.W. (2007). Prenatal diagnosis: Progress throught plasma nucleic acids. Nature Reviews Genetics, 8(1), 71-77.

McConnell, S. R. (2000). Assessment in early intervention and early childhood special education: Building on the past to project into our future. Topics in Early Childhood Special Education; 20(1), 43-48.

Milli Eğitim Bakanlığı. (1997). 573 Sayılı Özel Eğitim Hakkında Kanun Hükmünde Kararname. Erişim adresi: http://orgm.meb.gov. tr/meb_iys_dosyalar/2012_10/10111011_ozel_egitim_kanun_hukmunda_kararname.pdf. Erişim tarihi: 27.02.2019.

Milli Eğitim Bakanlığı. (2018). Özel Eğitim Hizmetleri Yönetmeliği. 07.07.2018 Tarih ve 30471 Sayılı Resmî Gazete. Erişim adresi: https://orgm.meb.gov.tr/meb_iys_dosyalar/2018_07/09101900_ozel_egitim_hizmetleri_yonetmeligi_07072018.pdf Erişim tarihi: 27.02.2019.

Öner, N. (1994). Türkiye'de Kullanılan Psikolojik Testler: Bir Başvuru Kaynağı (2. Basım). İstanbul: Boğaziçi Üniversitesi Yayınları.

Özak, H., Vural, M. ve Avcıoğlu, H. (2008). Rehberlik Araştırma Merkezi Müdürlerinin Gönderme Tanılama Yerleştirme İzleme ve Değerlendirmeye İlişkin Görüş ve Önerileri. Abant İzet Baysal Üniversitesi Eğitim Fakültesi Dergisi, 8(1), $189-206$.

Özaltun Ş. C., Güler S. ve Şengelen M. (2015). Sağlık Taramaları. HUTF Halk Sağı̆̆ı AD. Toplum Eğitim Sunumları. Erişim adresi: http://www.halksagligi.hacettepe.edu.tr/diger/toplumayonelik/tarama.pdf. Erişim tarihi: 20.03.2018.

Özgüven, İ. E. (1994). Psikolojik testler. Ankara: Yeni Doğuş Matbaası.

Projeiq. (2015). Anadolu Sak Zekâ Ölçeği-ASIS. Erişim adresi: https://www.projeiq.com

| Kastamonu Eğitim Dergisi, 27(6), 2019| 
Raven, J. ve Summers, B. (1990). Manual for raven's progressive matrices and vocabulary scales: research supplement, No $3(2$. Ed). Oxford: Oxford Psychological Press.

Sucuoğlu, B. (2012). Otizm Spektrum Bozukluğu olan Çocukların Değerlendirilmesi. E. Tekin-iftar (Ed.), Otizm Spektrum Bozukluğu Olan Çocuklar ve Eğitimleri içinde (s. 47-82) Ankara: Vize Basın Yayın.

Sürmeliler, E. (2005). Pretanal tanı amaçlı, kromozom analizi gerektiren amniyosentez endikasyonları ve sonuçlarının değerlendirilmesi. Yayınlanmamış uzmanlık tezi, Çukurova Üniversitesi, Tıp Fakültesi, Adana.

Şirin, H., Özkan, S., Karaşahin, E. F., Topal, S. ve Bilgin, S. (2015). Ankara İlinde Yapılan Yuvalandırılmış Olgu-Kontrol Çalışmasında 2009 Yılında Konjenital Hipotiroidi Tanısı Alan Yenidoğanlarda Risk Faktörleri ve Tarama Testinin Değerlendirilmesi. Pediatric Research, 2(2), 78-83.

Taylor, R. L., Richards, S. B. ve Brady, M. P. (2005). Mental retardation: Historical perspectives, current practices, and future directions. Boston: Allyn \& Bacon.

Tekin-İftar, E. (2011). Down sendromu. E. S. Batu (Ed.), 0-6 yaş arası down sendromlu çocuklar ve gelişimleri (2. Baskı) içinde (s. 9-38). Ankara: Kök Yayıncılık.

Üstü, Y. ve Uğurlu, M. (2016). Ulusal Erken Tanı ve Tarama Programı: Kistik Fibrozis National Early Diagnosis and Screening Program: Cystic Fibrosis.

Wolf, B. (2015). Why screen newborns for profound and partial biotinidase deficiency?. Molecular Genetics and Metabolism, 114, 382-387. DOI: http://dx.doi.org/10.1016/j.ymgme.2015.01.003.

Yüreğir, Ö. Ö., Büyükkurt, S., Koç, F. ve Pazarbaşı, A. (2012). Prenatal tanı. Arşiv Kaynak Tarama Dergisi, 21(1), 80-94.

Zaiman, H. H. (2001). Dynamic testing in selection for an educational programme: assessing south african performance on the raven progressive matrices. International Journal of Selection and Assessment, 9(3), 258-269.

Zerjav Tansek et al. (2015). Phenylketonuria screening and management in southeastern Europe - survey results from 11 countries. Orphanet Journal of Rare Diseases. (10)68, 1-7. DOI: 10.1186/s13023-015-0283-0. 